\title{
Language Shift and Maintenance: A Case Study of Pakistani-American Family
}

\author{
Samina Sarwat ${ }^{1}$, Haris Kabir ${ }^{1}$, Numra Qayyum ${ }^{1} \&$ Muhammad Akram ${ }^{1}$ \\ ${ }^{1}$ Department of Humanities and Social Sciences, Khwaja Fareed UEIT, RYKhan, Pakistan \\ Correspondence: Dr. Samina Sarwat, Head of The Department of Humanities and Social Sciences, Khwaja \\ Fareed University of Engineering and Information Technology, Rahim yar Khan. E-mail: \\ waheed.shahzad@kfueit.edu.pk
}

Received: September 17, $2020 \quad$ Accepted: October 25, $2020 \quad$ Online Published: November 13, 2020

doi:10.5539/ijel.v11n1p86 URL: https://doi.org/10.5539/ijel.v11n1p86

\begin{abstract}
This article investigated the language shifting and maintenance in daily life conversation of family resided in USA. The sources of data involved the participation of three generations, 7 members total in number, including 4 adults and 3 children. The observation was of observer participant type. The family was observed through video call, continually 10 hours a day in natural environment during 5 days period. Moreover, the interview was continued for 20 minutes, from 4 members of the family, 2 members from 1st generation and 2 members from 2nd. The collected data revealed that the second generation preferred to talk in L2-English but they switched to LI -Punjabi/Urdu when needed. First generation, the older ones talk in LI Punjabi/Urdu. They rarely switched to L2 to facilitate their younger generation mostly they tried to maintain their LI by code switching when interacting with each other even with their young family members. It was a pure qualitative study. Findings suggest that the preference to L2 was to succeed their younger generation in their academic and social life. They consider their social and economic benefits more important than their ethnic linguistic identity.
\end{abstract}

Keywords: daily conversation, language shift, maintenance, ethnic linguistic identity

\section{Introduction}

\subsection{Introduction to Topic}

One cannot challenge the importance of a language in a society because it is the one main factor which Envisage a society. In case of immigrants it becomes mandatory for them to learn the language of host country. Many researches had been done to evaluate how the knowledge of the 2nd language or host country have changed the way of earning income and also make them how to use opportunity in the market. Some studies show existence of deep relationship (Chiswick \& Miller, 2015; Dustmann \& Fabbri, 2003; Tainer, 1988), although others do not reveal consequential findings. Language shift are the important constitutive of language variation that assures a language change and development in question Causes of language shift varies with context. This study investigated the language shift and maintenance of a Pakistan-American family in their daily life conversation. English has become a globalize language and has also become a tool for gaining chances in foreign countries for those who are living foreign countries. It has also become a key tool for earning, gain fame and nationality for emigrants. According to a survey, nearly 1.7 billion people of the world speak English and in United States native-born Americans are very well aware of the welfare of English language learning and also waiting for English language learning classes because they know how multilingualism will be beneficial for economy and open opportunities for bright future. English language learning skills are not just beneficial for the immigrants but also for those who have wish to get global economy.

\subsection{Who Are Pakistani-Americans?}

Wikipedia defines Pakistani-Americans as those Pakistanis who moved to reside in USA are known as Pakistani Americans. The term may also refer to the people who hold both Pakistanis. However, the linguistics identity and language fluctuation are helpful to establish a cultural identity to shift a language (Fishman, 1989). Fishman indicates the demographic concepts that disrupts in language shifting are social and cultural identity.

\subsection{Pakistani Diaspora}

According to a survey nearly half a million population of Pakistan call United States their home. Their earning 
and pedagogical stander of this Pakistani-American community is significantly higher than those in the US population in general. Doctors, engineers, lawyers, accountants, journalists, politicians, business executives, professional sports team managers and owners, artists, actors, entrepreneurs, salespeople, policemen, soldiers, convenience store clerks, and taxi, bus and truck drivers are included in this term. US is the 5th most popular destination among Pakistan-born international migrants and the 6th largest source of remittances to Pakistan. According to the report of MPI Migration Policy Institute as cited by (Hooper \& Groves, 2017) number of Pakistani immigrants in US was 453,000000 as of 2013 and Pakistani individual account for about 0.8 percent of United State' total foreign-born population. Of these, 273,000 were born in Pakistan and the remaining 180,000 are US-born. The Pakistani-American population has more than doubled in the last decade due to increased immigration, according to US Census data. The population of Pakistani immigrants has been growing since 1980 when approximately 30,000 Pakistanis were US residents.

\subsection{Literature Review}

Language maintenance and language shift, as contact phenomena, have received a remarkable attention since the publication of (Fishman, 1989) pioneering work Language Loyalty in the United States. For case studies of language shift and maintenance developed countries has been taken as subject by researchers. According to García (2010) when a community of bilingual speakers gradually stops speaking its one language in the favor of other is called language shift. Language shift may be linguistic rejuvenating to preserve language. Language promotes protection of ethnic minority and reviving of immigrant languages. Although, diminishing languages pursuing socio culture reverberation were step by step replaced by leading languages the willing attempts to switch a shift can preserve and reconstruct structural and functional rightness of diminishing language. Mostly cited factors are economic, inedible, and ideological consideration. According to the report of Gal (1979) indicates the affected factors that caused economic change in the small village of Oberwart. According to Fishman (1989) comprehensive constituent of language in worldwide, both local and global may be caused of language shift that have advantage coincide of different dialects. The one important linguistics doctrine that may consider language shift is the culture of represent country. In addition to this shifting of a language has been examined for its structural and functional quantity because language shift means the change in its lexical and grammatical structure (Holmes, 2013). The other main feature examined by Holmes (2013) is economic change indicates whether the members of a community change their language because of financial benefits or any other reason but getting a job in foreign countries indicates the reason of learning a global language to get economic benefits. For example, in many countries including Pakistan English is considered an official language therefore people prefer to learn English language than social group of people would prefer to learn English for economic benefits Holmes (2013). For example, according to MacKinnon (1990) migration of Gaelic speakers from Scottish Highlands to English-speaking areas in the XIX century in search of work was the main reason of language's eventual decline. The social and economic goals of people in the community are also very important in terms of the speed of language shifts (Holmes, 2013).

\section{Research Methodology}

Previously different studies on language shift and maintenance were negotiated by different methods like qualitative, quantitative and approaches in different linguistics context. Different methods of research use to check the scope of approaches in educational research are used to gather data to clarify interference and prediction of language (Cohen, Manion, \& Morrison, 2013), Considering the objectives and nature of study qualitative study to be used as the method for research. Qualitative methods like interview and observation are used for research. Quantitative research is a method used to probe the problems relating to society or human beings that build up a complex and holistic view of social human problem. This research is conducted in natural settings.

\subsection{Data Collection}

Data is collected with the help of two research tools:

\section{1) Observation; observer as a participant}

\section{2) Interviews}

It was difficult to approach other families for wide study, therefore this study is limited to one family for research purpose. Data sources involved the participation of three generations; 7 family members; 4 adults and 3 children, who have been living there for 20 years. Profile of the family members are given below in table. Gafaranga and Torras i Calvo (2001) and Khemlani-David (1998) have already used these tools and method for the similar inquiries and objectives. 
The participants were observed 10 hours continually through the period of 5 day, with the help of video calls. The observation was all done in natural setting of home domain. the data was gathered with the help of audio recordings and field notes. Interview session was done with the elder members of family. Interviews were semi structured on the theme related to the research objectives. which lasted for 20 minutes. The audiotapes of natural recordings and interviews were transcribed by researcher after listening to them carefully. English translation is in while Urdu and Punjabi code switching has been given in Italics. The collected data were then analyzed qualitatively. We have taken some extracts from the recordings due to the word's restriction. the extract provides us some idea of the language shift and maintenance in their day to day conversation.

\section{Data Analysis}

Table 1. Data analysis

\begin{tabular}{lllllllll}
\hline No. & Participants & Status & Age & Generation & Education & Language Spoken & Place of Birth & $\begin{array}{l}\text { Years Lived } \\
\text { In US }\end{array}$ \\
\hline 1 & Mr. Akb & $\begin{array}{l}\text { Grand } \\
\text { father }\end{array}$ & 79 & $1^{\text {st }}$ generation & Middle & Punjabi/ Urdu & Born in Pakistan & 27 \\
2 & Mrs.Akb & $\begin{array}{l}\text { Grand } \\
\text { mother }\end{array}$ & 77 & $1^{\text {st }}$ generation & Primary & Punjabi/ Urdu & Born in Pakistan & 15 \\
& & & & & & \\
3 & Mr.Asi & Father & 42 & $2^{\text {nd }}$ generation & Fsc & Punjabi/Urdu/English & Born in Pakistan & 23 \\
4 & Mrs.Asi & Mother & 32 & 2nd generation & Matric & Punjabi/Urdu/English & Born in Pakistan & 15 \\
5 & Sar & Son & 13 & 3rd generation & $8^{\text {th }}$ grade & English & Born in US & 13 \\
6 & Aya & Son & 9 & 3rd generation & $4^{\text {th }}$ grade & English & Born in US & 9 \\
7 & Anay & Son & 6 & 3rd generation & $2^{\text {nd }}$ grade & English & Born in US & 6 \\
\hline
\end{tabular}

In previous studies as discussed in literature review the language shift and maintenance was investigated in larger population while this study is based on limited population. We have just focused a family's interactional practices. The collected data showed the sudden language shift of the participants from Punjabi/Urdu bilingualism to English Monolingualism of third generation during different situations in their daily life language use (Anthonissen, 2009). While 1st and 2nd generations prefer to speak in English. Through the observation we have witnessed that 2 nd generation somehow do code switching to facilitate 3rd generation but 1st generation, the older ones stick to their MT. In participants conversation language maintenance was noticed through code switching and code mixing of Punjabi/Urdu. We noticed that the 3rd generation participants replied in English whatever the dealing is, whether the conversation is in English or Punjabi/Urdu. They just use MT when they feel that the elder members of family will not understand them. In case of 2 nd generation code switching was notice, they sometimes response to each other in English and suddenly switch to Punjabi/Urdu. While 1st generation prefers to use Punjabi/Urdu with some expressions in English.

\subsection{Interactional Practices Across Three Generations}

Language shift happens when the language of a wider society means majority displaces the minority mother tongue language over time in migrant communities or in communities under military occupation. "when a community who share a native language abandon it, and collectively shift to speaking another one instead" Language shift is always preceded by multilingualism. This same view is pointed by Webb and Sure 2000 as cited by Stahlke (2002), who refer "language shift is an action through which the speakers of a community starts to speak another language of other community until they eventually use only the second language, even in personal and intimate contexts". We have noticed in interactional practices of all the three generations that 1 st and 2nd generation prefer their mother tongue Punjabi/Urdu while 3rd generation use English as a convenient language.

\subsection{Extract 1: Conversation in Dining Room}

1) Chlo bacho a jao jaldi say. [come on, children come here Hurry up] Aya you cannot use this, its family time.

2) Aya: family time.... Ok.

3) Anay: Dddy, there is a boy in my class, he said he was born in 1989.

4) Daddy: 1989??? Are you okay?

5) Mom: Baita wo upnay brother ka kah rha hoga. [he must be kidding]

6) Daddy: Is he like Sido lala's [aunt] old. Sido lala was born in 1989. 
7) Aya: hain? [what!] Children amazed

8) Mom: You know? I think so.

9) Daddy: Ya... she is 27,28 or may be 30 . I think so.

10) Daddy: He must be kidding?

11) Mom: Usko kho ap ghost ho. Hahahah [laughing], [tell him that he is a ghost]

12) Daddy: Your friend Omar's dad call me today.

13) Sare: What did he say?

14) Daddy: He said my son and and your son are getting long very good. Is he right?

15) Mom: kha lia sub nay khana btaya nai kaisa bna? [everybody ate lunch but nobody told me how was it?]

16) Daddy: Kheeray di gal kar raen ain? [Are you talking about cucumber]

17) Mom: Api tanu pasand a gya. [Api did you like it]

18) Mrs AKB: Han mzay da pakya ay. [yes, its tasty]

\subsection{Extract 2: After Coming Back from School}

1) Sar: itni khuli hoi thi? [It was that much open]

2) Mom: window?

3) Sar: Han g wind itni zor say chali k main wo jo k gira. [Yes,the wind blew with so much force that I fell]

4) Mom: Jhota [liar]

5) Sar: No, I swear I fell. Like It pushed me a lil bit and then I literally tripped down like something on the floor.

6) Mom: Ahan. Aj wind hai hi bht. Sir main dard horha. [right the wind was so strong today. I have headach] I need tea.

7) Sar: Daddy, I took a shortcut getting home today. Is it not? It took me shorter.

8) Daddy:Tum whan kia kar raye thay? [what were you doing there?]

9) Sar: I went with Daniel. He said it's a shortcut.

10) Daddy: Daniel k lyay shortway hai tmaray liay nai. [it's a shortcut for Daniel not for you.]

11) Sar: Ok.......

We have examples that M r. and Mrs. ASI use both English and their mother tongue when talking to each other and with their children. There are some instances in which we noticed that Mr. ASI mostly preferably used English while talking to their children then Mrs. Asi. As we know that both are Pakistani born but they had to use English in their social circles and outside home in getting economic benefits. Children of 3rd generation prefer English while talking to each other. It is interesting to see that elder members mostly used their MT when they had fierce tone or giving order to their children e.g., in turn 1 of extract 1 and turn 8 of extract 2.

\subsection{Extract 3: Conversation in Living Area}

1) Mr. Akb: How are you doin bacho? [Children]

2) Sar: Doing well dada. How are you?

3) Mr. Akb: Thik hn. [I am good]. Abbi ji kidar nay tairay, mairi doctor kol appointment si aj di? [where is your daddy I have appointment with doctor today]

4) Mrs. Akb: Amn [Mrs Asi] unnon phone kar k kah time nal kar a jaway. [call him and say to come on time]

5) Mrs Asi: acha karti hn pata, yaad tu karwaya tha main nay. [ok I'll, I reminded him]

In extract 3 we noticed that how elder family members use English with 3rd generation but then they suddenly switch to Punjabi/Urdu to talk with rest of family members.

[see turn 1 and 3]

\subsection{Medium Request and Negotiation}

The researchers wanted to prefer "medium request," to comprehend fact. It is considered a good starting point of language debates but later on it specified by Gafaranga and Torras i Calvo (2001) as "medium negotiation".

A language negotiation sequence (Auer, 1984) "when the two or more community of the people oppose to use 
language for interaction rather than economic benefits, negotiation happens, and ends as soon as one of them 'gives in' to the other preferred language". SO, medium request is the descent refusal by younger generation to continue their conversation in English.

\subsection{Extract 4: Call from Pakistan}

1) Mom: Sarem who is calling?

2) sar: It's from nano's home.

3) mom: Ok I am coming.

After few minutes

4) Mom: Aya N.. and S.. lala [aunts] wants to talk to you.

5) Ayan: Aslamualaikum. [greeting]

6) lala: Walaikumusalam. Kaisay ho? [Greetings. How are you?]

7) Aya: I am good.

8) lala: Dado ko kal kia kaha thaw o gussay ho rahi then. [what did you say to your grandmother yesterday, she was getting angry]

9) Aya: What?

10) Lala: Ap btao. [you tell.]

11) Aya: I didn't say much.

12) lala: Wo $\mathrm{k}$ ah rahin thi English main mgh say argue kar rha tha. [She said he was arguing me in English]

13) Aya: Mommy your sisters are embarrassing me...

In extract 4 it is noticed that $3^{\text {rd }}$ generation talks in English even when their elder person is resisting talking in MT. In turn 12 of extract 4 we noticed that Mrs. Akb doesn't know English. while the participant argued with her in hi L2 which she didn't get. These are the advantages which younger generation enjoys with L2.

\section{Language Maintenance:}

When someone willingly try to protect its MT it is called language maintenance. 'Intersentential' and 'Intrasentential' are two types of code switching. Intersentential is the switching from one language to another between different sentences while intrasentential is the code switching within a sentence.

\subsection{Extract 5}

1) Mr Akb: Bacho chalo, get ready for masjid, namaz ka time hogya. [let's go kids]

2) Mrs Asi: Come on kids, hurry up, waddu karo. [do ablution]

3) Sar: Ok.

4) Aya: Just a minute. Iam getting ready.

5) Mr Asi: Aya topi khan h, go get it. [where is you cap]

6) AYA: G, Abbi G. [Ok, DADDY]

7) Mrs Asi: Sare juldi karo, they are ready to go. [Hurry up]

8) Sar: Coming.

In the above extract we noticed intrasentential code switching through the use of Islamic lexical items. It is actually the way to maintain mother tongue. We have already seen this type of code switching in turn 8 of extract 2 and turn 1 of extract 3 . In urge, fierceness and sometimes in imperative sentences elder members used MT to make it more effective. Like in turn 8 of extract 2 where father is scolding his son in his MT.

\subsection{Practical Usefulness of Language vs. Ethnolinguistic Identity}

All the four members of 1 st and generation were interviewed which clearly showed their affiliation with L1. which also gave detail of the factors causing the language shift in family. All the elderly was crystal clear about their language plans.

I am a Pakistani Muslim and if I don't speak Punjabi/Urdu, all the day it doesn't mean that I am losing my identity. I go to Masjid daily. I make sure that my children are learning Quran. With all these things I think I keep my identity and my ethnicity safe. On the other hand, we cannot force our children to speak their MT all the time. 
Children will learn English anyway. In US they appreciate students who are multilingual. it is also important for them to be fluent in L2 because it is necessary to be a part of such modern and fast culture and also to be succeed in future and making their career.

[Mr. Asi]

Mr. Asi better understands the importance of foreign language in a foreign country. You cannot be living like an alien in a society without knowing its language. He has same point view as the participants of (Khemlani-David, 1998). Who had a faith on the thing that has less to do with the identity? To diminish the alienated feeling, one has to learn the relevant language of place to get social and economic benefits.

Yes, at home we prefer to speak in L1 because that makes us feel connected with our culture/Pakistani culture. I keep reminding them to speak and how to speak because in my point of view learning MT doesn't mean that they will not get fluent in L2. In US our children's language is English, which they speak all the day, at their schools, with their friends and even at home with each other. But at the same time, I cannot deny the importance of English for my children because in getting success and in making career they will surely need this.

[Mrs. Asi]

In the above abstract we noticed that Mrs. Asi willingly forced their children to learn MT but because of her husband's soft attitude towards English didn't allow it fully. Which is an example of language maintenance. She also admitted the importance of English. From these extracts we came to know that how elderly members of family prefer English over MT to facilitate their children. They think that learning English is obviously beneficial for academic as well as career success. They said that learning English will not lose their identity because they practice it at home and it is not a wise decision to force them to L1 because L2 is necessary to merge in the society.

\section{Results and Discussion}

The findings reveal that there is a clear evidence of language shift among Pakistani-American immigrants. They preserve linguistic identity or improve their children's English language skills at the same time that are essential for their active professional career. With the time the domestic forces evolved or there are factors like educational, social and economic factor which opened the way for English language learning. Language was more frequent and mostly seen than language maintenance. Both intrasentential and intersentential switching were seen but former was much more than the latter. It was noticed that the 3rd generation rarely preferred Punjabi/Urdu in their linguistic practice s but 1 st and 2nd generation to facilitate the medium request shift their language. The elder generations usually switch when they are using religious lexical items, scolding and giving instruction to younger ones.

\section{Conclusion}

The conclusion to be drawn from the presented data is that there are different factors which are causing language shift and maintenance in the family who has been living in US for 27 years. The primary findings of the study showed that the first generation find ease in their MT. 2nd generation speaks in English but they showed sudden switch from L2 to L1 to facilitate their members but for their children they prefer L2 because they thought it is necessary to get social, academic and economic benefits. Also, their younger generation's polite refusal to L1, negotiation of their medium for English becomes the cause of language shifting. 2nd generation doesn't bother in surrendering in front of L2 to enjoy the benefits.

This study cannot be generalized due to its limited sample. We took only one immigrant family whose mother tongue was Punjabi/Urdu. The study was a humble try to investigate the set objectives. It was basically for Pakistani Punjabi families. So, the language shift and maintenance may be similar in other Punjabi immigrant families.

\section{References}

Anthonissen, C. (2009). Bilingualism and language shift in Western Cape communities. Stellenbosch Papers in Linguistics PLUS, 38, 61-76. https://doi.org/10.5842/38-0-48

Auer, P. (1984). Bilingual conversation. John Benjamins Publishing. https://doi.org/10.1075/pb.v.8

Chiswick, B. R., \& Miller, P. W. (2015). International migration and the economics of language. Handbook of the $\begin{array}{lllll}\text { Economics of International Migration, 1, 211-269. Elsevier. } & \end{array}$ https://doi.org/10.1016/B978-0-444-53764-5.00005-0

Cohen, L., Manion, L., \& Morrison, K. (2013). Research methods in education. Routledge. 
Dustmann, C., \& Fabbri, F. (2003). Language proficiency and labour market performance of immigrants in the UK. The Economic Journal, 113(489), 695-717. https://doi.org/10.1111/1468-0297.t01-1-00151

Fishman, J. A. (1989). Language and ethnicity in minority sociolinguistic perspective. Multilingual Matters.

Gafaranga, J., \& Torras i Calvo, M.-C. (2001). Language versus medium in the study of bilingual conversation. International Journal of Bilingualism, 5(2), 195-219. https://doi.org/10.1177/13670069010050020401

Gal, S. (1979). Language shift: Social determinants of linguistic change in bilingual Austria. New York: Academic Press.

García, O. (2010). Languaging and ethnifying. Handbook of language and ethnic identity. Disciplinary and Regional Perspectives, 1, 519-534.

Holmes, J. (2013). An introduction to sociolinguistics. Routledge. https://doi.org/10.4324/9781315833057

Hooper, K., \& Groves, S. (2017). A comparative analysis of the migration and integration of Indian and Chinese immigrants in the United States. Migrant Integration Between Homeland and Host Society, 2, 211-231. Springer. https://doi.org/10.1007/978-3-319-56370-1_12

Khemlani-David, M. (1998). Language shift, cultural maintenance, and ethnic identity; a study of a minority community: The Sindhis of Malaysia. International Journal of the Sociology of Language, 130, 67-76. Walter de Gruyter, Berlin/New York. https://doi.org/10.1515/ijsl.1998.130.67

MacKinnon, K. (1990). A Century on the Census: Gaelic in twentieth century focus. Paper presented at the Gaelic and Scots in Harmony: Proceedings of the Second International Conference on the Languages of Scotland.

Stahlke, H. F. (2002). African Voices: An Introduction to the Languages and Linguistics of Africa. JSTOR. Linguistic Society of America, 78(4), 776-778. https://doi.org/10.1353/lan.2003.0058

Tainer, E. (1988). English language proficiency and the determination of earnings among foreign-born men. Journal of Human Resources, 108-122. https://doi.org/10.2307/145847

\section{Appendix A}

\section{Interview questions}

1) Do you want your children to grow up with their mother tongue?

2) Do you think they will be as fluent in their mother tongue in future as you are?

3) What hurdles you face to maintain your mother tongue?

4) Have you ever been strict to your children in learning and what were the consequences?

5) In there any benefit in sticking to English and ignoring your MT?

6) What measures should be taken to ensure bilingualism?

7) How would you protect your language?

8) What language do you prefer to speak with your children and why?

9) Do you think your MT is your identity?

10) What is identity? What is your identity?

\section{Copyrights}

Copyright for this article is retained by the author, with first publication rights granted to the journal.

This is an open-access article distributed under the terms and conditions of the Creative Commons Attribution license (http://creativecommons.org/licenses/by/4.0/). 